\title{
TRANSMISSION LINE THEORY BASED TWO LAYER MODEL FOR DETERMINING SOIL MOISTURE
}

\author{
P. Mishra*, D. Singh
}

Department of Electronics and Computer Engineering, Indian Institute of Technology Roorkee, Roorkee Roorkee, (UK)-247667, India- (er.poojamisra, dharmfec) @gmail.com

KEY WORDS: Soil Moisture, Impedance, Genetic Algorithm, Dielectric Constant.

\begin{abstract}
:
Present paper deals with the task of estimating soil moisture under vegetation cover by using transmission line theory based two layer model. The two layer model measures the impedance of both the layers namely, soil and vegetation. This impedance is the function of dielectric constant and thickness of both the layers. For known dielectric constant and height of vegetation layer, dielectric constant of soil was determined for certain thickness of soil layer using genetic algorithm (GA). The soil moisture value was retrieved from dielectric constant of soil by using Topp et al.,(1980) relationship. Retrieved soil moisture values were in good agreement with observed values.
\end{abstract}

\section{INTRODUCTION}

Soil moisture estimation has gained much attention due to its importance in various applications, such as hydrology (Schmugge et al., 2002), agriculture (McNairn et al., 2004), etc. In past several methods have been developed for estimating soil moisture over bare soil surface (Oh et al., 1992; Dubois et al., 1995) at microwave bands. Application of these algorithms over vegetated surfaces causes under-estimation of soil moisture (Shi et al., 1997). These methods also show some limitation in estimating soil moisture under vegetated surface because vegetated surface represent multiple scattering effect i.e., diffuse scattering from vegetation and surface scattering from underlying soil. In other terms, for vegetation covered soil, the emission of bare soil surface is very much influenced by the canopy layer which attenuates the soil emission and adds its own emission (Jackson et al., 1982).The separation of scattering contribution of both the media (vegetation and soil) using backscattering coefficient is still a very challenging task. Therefore, in this paper two layer model has been proposed and applied for estimating soil moisture under vegetation cover. Earlier this method has been used by several researchers for different applications, like, estimation of thickness of burnt coal seam (Tetuko et al., 2003a; Tetuko et al., 2003b), and topsoil of semiarid area (Al-Bilbisi et al., 2004). Mishra et al., (2012) have used the capability of this method in estimation of the thickness as well as moisture of two different layers of soil.

By using the concept of transmission line theory, series impedance of any media can be obtained as a function of dielectric constant and width (thickness) of that media. Therefore in this paper two layer model has been constructed assuming first layer as vegetation having thickness $t_{v}$ and complex dielectric constant $\varepsilon_{l}$ and second layer as soil layer having thickness $t_{s}$ and dielectric constant $\varepsilon_{2}$. For known dielectric constant and height of vegetation layer calculated during field survey, dielectric constant of soil was determined for certain thickness of soil layer using genetic algorithm (GA). The soil moisture value was retrieved from real part of complex dielectric constant of soil by using well-known polynomial relation proposed by Topp et al.

The present approach has been successfully evaluated on Cband radarsat-2 quad-pol data. The retrieved soil moisture values show the good agreement with the observed values of soil moisture.

\section{STUDY AREA AND DATA SET}

\subsection{Study area}

Present study has been performed over Roorkee region of India. The proposed approach has been evaluated on C-band (5.405 $\mathrm{GHz}$ ) Radarsat-2 quad polarimetric data acquired on 31st May, 2011.

Ground truth survey was carried out over the study area on same date of image acquisition and two fields of sugarcane were selected as the test area. A total of 10 samples were collected from test area and fresh weight of samples, plant height, leaf area index, leaf thickness, etc., were also measured.

\section{METHODOLOGY}

The two layer model has been developed for modelling the scattered wave from two layers namely, vegetation and soil using the concept of transmission line theory. The whole procedure and physical significance of the model has been discussed below:

\subsection{Two layer model}

Two layer model was developed by assuming that media is composed of two layers namely, vegetation and soil having thickness $t_{v}$ and $t_{s}$, respectively. There is infinite length of air above vegetation layer. The two-dimensional diagram for this model is shown in Fig.1. The analysis of two-layer model was performed by using the concept of transmission line theory. By taking the advantage of transmission line theory, impedance of 
each layer can be calculated as a function of dielectric constant and thickness of those layers. The equivalent circuit of this twolayer model is shown in Fig.2, where $Z_{C l}$ and $Z_{C 2}$ symbolize effective series impedance of vegetation and soil layer, respectively, respectively while $Z_{L 1}$ and $Z_{L 2}$ symbolize parallel impedance of vegetation and soil layer, respectively. $Z_{T}$ is the total input impedance. For simplicity, the parallel impedances of vegetation and soil layer i.e., $Z_{L I}$ and $Z_{L 2}$, respectively are considered as zero in the analysis (Tetuko et al., 2003a; Tetuko et al.,2003b; Al-Bilbisi et al., 2004; Mishra et al., 2012).

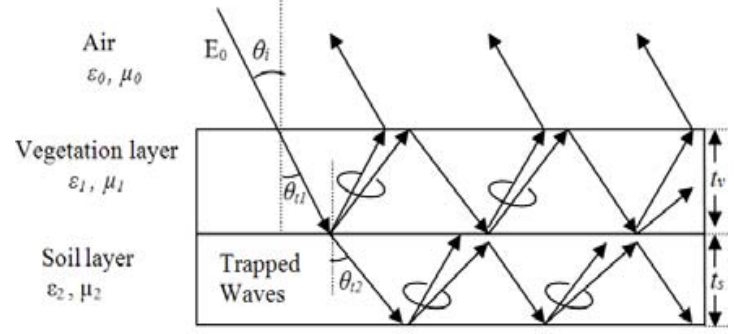

Fig.1. Two-dimensional diagram for two-layer modelling approach (AlBilbisi et al., 2004)

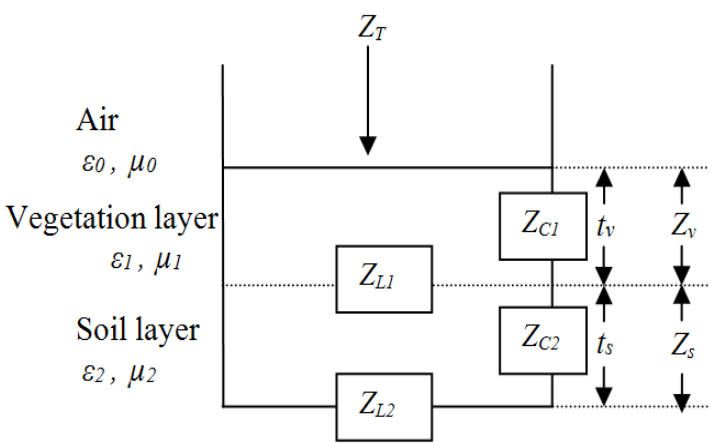

Fig.2. Equivalent circuit of two-layer model (Al-Bilbisi et al., 2004)

Using the concept of transmission line theory, impedances of vegetation and soil layers i.e., $\mathrm{Z}_{\mathrm{v}}$ and $\mathrm{Z}_{\mathrm{s}}$, respectively, were determined as,

$$
\begin{aligned}
& Z_{v}=Z_{C 1} \frac{Z_{L 1}+Z_{C 1} \tanh \gamma_{C 1} t_{v}}{Z_{C 1}+Z_{L 1} \tanh \gamma_{C 1} t_{v}} \\
& Z_{s}=Z_{C 2} \frac{Z_{L 2}+Z_{C 2} \tanh \gamma_{C 2} t_{s}}{Z_{C 2}+Z_{L 2} \tanh \gamma_{C 2} t_{s}}
\end{aligned}
$$

where $\gamma_{C l}$ and $\gamma_{C 2}$ are propagation constants of vegetation and soil layer, respectively.

The total input impedance $Z_{T}$ seen looking towards vegetation and soil layers was determined by,

$Z_{T}=Z_{v}+Z_{s}$

After applying Snell's law, at the boundary between the air and vegetation layer, following relationship was obtained,

$\sin \theta_{i}=\sqrt{\varepsilon_{1} \mu_{1}} \sin \theta_{t 1}$

where $\varepsilon_{l}, \mu_{l}$ and $\theta_{t l}$ are complex dielectric constant, complex specific permeability and transmission angle of vegetation layer, as shown in Fig.1.

The incident wave $E_{0}$ was assumed to be a plane wave with incidence angle $\theta_{i}$. Considering incidence of plane wave $E_{0}$ from air to vegetation layer, the propagation constant was derived as,

$\gamma_{C 1}=j \frac{2 \pi}{\lambda} \sqrt{\varepsilon_{1} \mu_{1}-\sin ^{2} \theta_{i}}$

The effective series impedance of vegetation layer was obtained as
$Z_{C 1}=Z_{0} \sqrt{\frac{\mu_{1}}{\varepsilon_{1}}} \cos \theta_{t 1}$

where $Z_{0}$ is intrinsic wave impedance of free space (i.e., $120 \pi$ ohms). Now, equation (1) can be written as

$$
Z_{v}=\frac{Z_{0}}{\varepsilon_{1}} \sqrt{\varepsilon_{1} \mu_{1}-\sin ^{2} \theta_{i}} \tanh \left(j \frac{2 \pi t_{v}}{\lambda} \sqrt{\varepsilon_{1} \mu_{1}-\sin ^{2} \theta_{i}}\right)
$$

Similarly $Z s$ can be calculated. After obtaining impedances of both the layer, total input impedance $Z_{T}$ was calculated. The reflection coefficient is then determined by,

$$
\Gamma=\frac{Z_{T}-Z_{0} \cos \theta_{i}}{Z_{T}+Z_{0} \cos \theta_{i}}
$$

\subsection{Retrieval of effective dielectric constant of vegetation layer}

The complex dielectric constant of vegetation can be determined using Debye-Cole dual dispersion model (Ulaby et al., 1987).

$\varepsilon_{\text {veg }}=\varepsilon_{r}+v_{f w} \varepsilon_{f w}+v_{b} \varepsilon_{b}$

where $\varepsilon_{\mathrm{r}}, \varepsilon_{\mathrm{fw}}, \varepsilon_{\mathrm{b}}, v_{f w}$ and $v_{b}$ are non-dispersive residual component, dielectric constant of free water, dielectric constant of bulk vegetation-bound water mixture, volume fraction of free water and volume fraction of bulk vegetation-bound water mixture, respectively. They can be calculated as,

$$
\begin{aligned}
& \varepsilon_{r}=1.7-0.74 m_{g}+6.16 m_{g}^{2} \\
& \varepsilon_{f w}=4.9+\frac{75}{1+j f / 18}-j \frac{18 \sigma}{f} \\
& \varepsilon_{b}=2.9+\frac{55}{1+(j f / 0.18)^{0.5}} \\
& v_{f w}=m_{g}\left(0.55 m_{g}-0.076\right) \\
& v_{b}=4.64 \frac{m_{g}{ }^{2}}{1+7.36 m_{g}{ }^{2}}
\end{aligned}
$$

where $m_{g}$ is gravimetric moisture of vegetation which can be calculated as, (Ulaby et al., 1984);

$m_{g}=\frac{\text { wet weight of vegetation }- \text { dry weight of vegetation }}{\text { wet weight of vegetation }}$

In equations (11)-(12), $f$ is frequency in $\mathrm{GHz}$ and $\sigma$ is ionic conductivity in Siemens per meter. The value of $\sigma$ is taken as 1.27 Siemens/m (Ulaby et al., 1987).

The effective dielectric constant of canopy (i.e., $\varepsilon_{l}$ ) (Ulaby et al., 1986) can be calculated as,

$\varepsilon_{1}=\left[1+v f\left(\varepsilon_{\text {veg }}^{\beta}-1\right)\right]^{\beta}$

where $v f$ is volume fraction of canopy filled with vegetation and $\beta$ is the indicator of used dielectric mixing. In the present analysis refractive model $(\beta=0.5)$ has been used because it fits well for longer wavelengths $(\lambda>5 \mathrm{~cm})$ (Schmugge et al.,1992).

\subsection{Implementation of two layer model on SAR data}

After pre-processing radarsat-2 data using SARscape software, complex reflection coefficient was retrieved for $V V$ polarization over the test area representing sugarcane field. This reflection coefficient was used to obtain total impedance $Z_{T}$ from equation (8), with $\theta_{i}$ equals to $34.42^{\circ}$, for radarsat- 2 data.

In order to calculate impedance of vegetation layer apriori knowledge of effective dielectric constant $\varepsilon_{l}$ and width $t_{v}$ of 
vegetation layer was required. Therefore, a total of 10 samples were collected from two sugarcane fields. The samples were dried in oven at $80^{\circ} \mathrm{C}$ for 12 hours and gravimetric moisture $\left(m_{g}\right)$ was calculated by using equation (15). During survey height of vegetation layer (sugarcane) $t_{v}$ was obtained as $130 \mathrm{~cm}$. Volume fraction of canopy was obtained as 0.0012 . Now impedance of vegetation layer $Z_{v}$ was obtained from equation (7) for calculated dielectric constant $\varepsilon_{l}$ and plant height $t_{v}$. The series impedance of soil layer say, $Z_{\text {S(OBSERVED) }}$ was obtained by subtracting $Z_{v}$ from $Z_{T}$.

\subsection{Use of Genetic algorithm (GA) for retrieving dielectric constant of soil}

It was observed that impedance of soil layer say, $Z_{s \text { (CALCULATED })}$ was nonlinear function of dielectric constant $\varepsilon_{2}$ and soil thickness $t_{s}$. Since we are interested in measuring soil moisture in first few centimetres of soil surface, therefore $t_{s}$ was assumed to be $5 \mathrm{~cm}$ in the present analysis. Now in order to retrieve complex dielectric constant $\varepsilon_{2}$ genetic algorithm approach has been used. Genetic algorithm is optimization based approach which is used to determine maximum or minimum of any arbitrary function, depending upon the nature of problem (Tseng et al., 2008). The most critical step of genetic algorithm is proper selection of fitness function for accurate determination of solution close to optimal results (Mishra et al., 2012).The fitness function for the current problem is defined as,

Fitness $f n=\left|Z_{s(\text { CALCULATED })}-Z_{s(\text { OBSERVED })}\right|$

where $Z_{S(O B S E R V E D)}$ is the impedance of soil layer obtained from equation (3) after subtraction of $Z_{v}$ from $Z_{T}$, and $Z_{s \text { (CALCULATED) }}$ is impedance of soil layer which can be represented as follows:

$Z_{s}=\frac{Z_{0}}{\varepsilon_{2}} \sqrt{\varepsilon_{2} \mu_{2}-\sin ^{2} \theta_{i}} \tanh \left(j \frac{2 \pi t}{\lambda} \sqrt{\varepsilon_{2} \mu_{2}-\sin ^{2} \theta_{i}}\right)$

The complex dielectric constant of soil is given by,

$\varepsilon_{2}=\varepsilon_{2}{ }^{\prime}-j \varepsilon_{2}{ }^{\prime \prime}$

where real part $\varepsilon_{2}^{\prime}$ is the permittivity of soil whereas imaginary part $\varepsilon_{2}$ is the dielectric loss factor of soil After applying genetic algorithm on fitness function, complex dielectric constant $\varepsilon_{2}$ was retrieved.

\subsection{Retrieval of soil moisture}

The soil moisture is retrieved by using Topp et al.,(1980) relationship. This polynomial relates real part of complex dielectric constant of soil to volumetric soil moisture value $m_{v}$. It is given by,

$m_{v}=-5.3 \times 10^{-2}+2.92 \times 10^{-2} \varepsilon_{2}^{\prime}-5.5 \times 10^{-4} \varepsilon_{2}^{\prime 2}+4.3 \times 10^{-6} \varepsilon_{2}^{\prime 3}$

\section{RESULTS AND DISCUSSION}

Genetic algorithm was applied over the fitness function given in equation (17) and complex dielectric constant of soil was retrieved for $5 \mathrm{~cm}$ thickness of soil surface. The constraint boundaries for real and imaginary part of dielectric constant $\varepsilon_{2}$ were taken as (3-50) and (0.01-10), respectively.

Table-I- Soil parameters retrived from two-layer model

\begin{tabular}{|l|l|l|l|}
\hline & \multicolumn{2}{|l|}{ Average soil moisture } & $\begin{array}{l}\text { Average } \\
\text { permittivity } \\
\text { of soil }\left(\varepsilon_{2}\right)\end{array}$ \\
\hline & $\begin{array}{l}\text { Measured } \\
\text { through GA }\end{array}$ & $\begin{array}{l}\text { Ground truth } \\
\text { values }\end{array}$ & 23.77 \\
\hline Field 1 & 0.35539 & 0.369 & 27.22 \\
\hline Field 2 & 0.417668 & 0.434 & \\
\hline
\end{tabular}

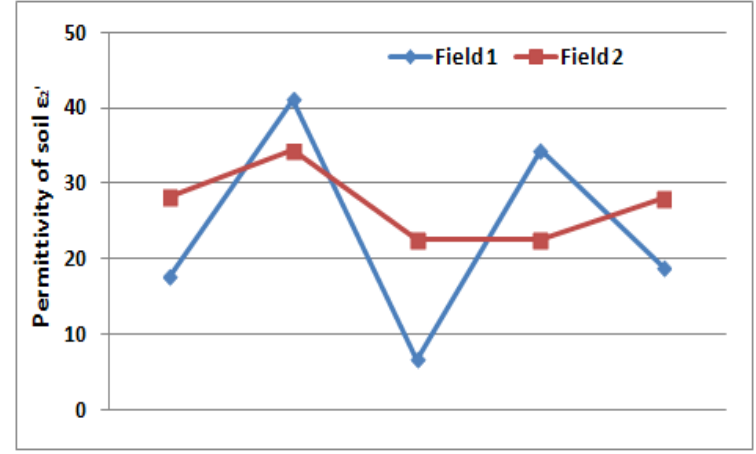

Fig.3 Permittivity of soil retrieved after application of genetic algorithm for the collected samples in two fields of sugarcane (5 samples were collected in each field).

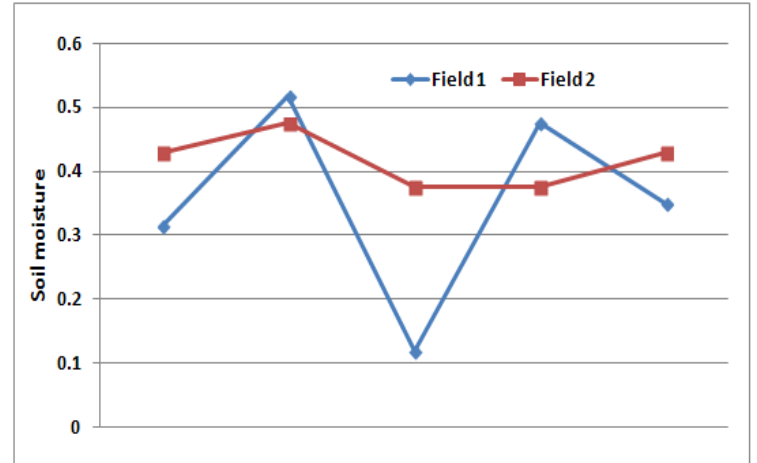

Fig.4. Soil moisture in first $5 \mathrm{~cm}$ layer of soil surface in two fields of sugarcane for the collected samples in two fields of sugarcane.

Fig. 3 shows the values of permittivity of soil i.e., $\varepsilon_{2}^{\prime}$ for both fields of sugarcane. These values were used to retrieve soil moisture values using equation (20). Fig 4 shows soil moisture in first $5 \mathrm{~cm}$ layer for two fields of sugarcane.

Table-1 shows the average value of permittivity and soil moisture retrieved by optimization using genetic algorithm (GA). Average value of soil moisture measured during ground truth survey is also shown in this table. It can be observed from the table that average soil moisture value is in good agreement with the measured ground truth-values of soil moisture in both the fields of sugarcane.

\section{CONCLUSION}

In the present paper transmission line theory based two layer model has been developed for estimating soil moisture under vegetation cover. For this purpose $\mathrm{C}$-band radarsat-2 data has been used. The proposed approach has been evaluated on $V V$ polarization of radarsat-2 data. In order to retrieve soil moisture under vegetation cover, two fields of sugarcane were selected in the study area. The developed two- layer model gives quite good results for retrieval of soil moisture. Retrieved soil moisture values are in good agreement with the observed ground truth values of soil moisture.

\section{REFERENCES}

Al-Bilbisi, H., Tateishi, R., Tetuko, S. S. J., 2004. A technique to estimate topsoil thickness in arid and semiarid areas of northeastern Jordan using synthetic aperture radar data. International Journal of Remote Sensing. 25(19), pp. 38733882. 
International Archives of the Photogrammetry, Remote Sensing and Spatial Information Sciences, Volume XL-1/W1, ISPRS Hannover Workshop 2013, 21 - 24 May 2013, Hannover, Germany

Dubois, P.C., VanZyl, J.J., Engam, T.,1995. Measuring soil moisture with imaging radars. IEEE Transactions on Geoscience and Remote Sensing, 33, pp. 915-926.

Jackson, T. J., Schmugge, T. J., Wang, J.R., 1982. Passive microwave sensing of soil moisture under vegetation canopies, Water Resour. Res., 18(4), 1137-1142.

McNairn, H., Brisco, B., 2004. The application of C-band polarimetric SAR for agriculture: A review. Can. J. Remote Sens., 30(3),pp. 525-542.

Mishra, P., Goel, S., Singh, D., and Srivastava, V., 2012. Multilayer modeling approach for measuring soil moisture and thickness using genetic algorithm. In :International Conference on Microwaves, Antenna Propagation and Remote Sensing (ICMARS), Jodhpur, India, pp. 489-492.

Oh, Y., Sarabandi, K., Ulaby, F.T., 1992. An empirical modal and an inversion technique for radar scattering from bare soil surfaces. IEEE Transactions on Geoscience and Remote Sensing, 30, pp. 370-381.

Schmugge, T. J., et al., 2002. Remote sensing in hydrology. Advances in Water Resources, 25,pp. 1367-1385.

Schmugge, T.J., Jackson, T.J., 1992. A Dielectric Model of the Vegetation Effects on the Microwave Emission from Soils. IEEE Transactions on Geoscience and Remote Sensing, 30(4), pp. 757-760.

Shi, J., et al., 1997. Estimation of soil moisture for vegetated surfaces using multi-temporal L-band SAR measurements. In: IEEE International Geoscience and Remote Sensing Symposium, 3, pp.1269,1271.
Tetuko, J.S.S., Tateishi, R., Takeuchi, N., 2003a. Estimation of burnt coal seam thickness in central Borneo using a JERS-1 SAR image. International Journal of Remote Sensing, 24, pp. 879-884.

Tetuko, J.S.S., Tateishi, R., Takeuchi, N., 2003b. A physical method to analyse scattered waves from burnt seam and its application to estimate thickness of fire scars in central Borneo using L-band SAR data. International Journal of Remote Sensing, 24, pp. 3119-3136.

Topp, G.C., Davis, J.L., Annan, A.P., 1980. Electromagnetic determination of soil water content: Measurements in coaxial transmission lines. Water Resource Research, 16(3), pp. 574 582.

Tseng, M.H., Chen, S.J., Hwang, G.H., Shen, M.Y., 2008. A genetic algorithm rule-based approach for land-cover classification. ISPRS Journal of Photogrammetry and Remote Sensing, 63(20), pp. 202-212.

Ulaby, F.T., Jedlicka, R.P., 1984. Microwave Dielectric Properties of Plant Materials. IEEE Transactions on Geoscience and Remote Sensing, GE-22(4), pp. 406-415.

Ulaby, F.T., Moore, R. K., and Fung, A.K., 1986. Microwave remote sensing :Active and Passive, Vol III : From Theory to Applications. Dedham, M.A: Artech House, App.E, pp. 2044.

Ulaby, F.T., El-Rayes, M.A., 1987. Microwave Dielectric Spectrum of Vegetation - Part II: Dual-Dispersion Model. IEEE Transactions on Geoscience and Remote Sensing. GE-25(5), pp.550-557. 